\title{
SUBMERSIBLE POP-UP BUOY for RF COMMUNICATION
}

\author{
William R. Macha \\ tel (619) 553-1962 \\ fax (619) 553-1959 \\ macha@nosc.mil
}

\author{
Kenneth E. Rogers \\ tel (619) 553-1521 \\ fax (619) 553-5229 \\ krogers@nosc.mil
}

\section{Naval Command, Control and Ocean Surveillance Center Research Development Test and Evaluation Division San Diego, California}

Abstract - Buoy geometries for ocean applications are as varied and diverse as the programs that give rise to their needs. NRaD is designing for ONR an autonomous, batterypowered, pop-up buoy system to provide RF communications between the sea surface and a remote ship or shore terminus, or an airborne or spaceborne repeater. This buoy system will act as a communication relay, sending and receiving data over an RF link, and shuttling that information, via fiber-optic link, to and from a sensor system on the ocean floor. Unique design features include an inherently positive, variabledisplacement spar; a variable-ballast chamber to regulate surface exposure; and a self-compensating tethermanagement/counterbalance system. Four micro-controllers distributed throughout the buoy system control all buoy parameters. An innovative antenna configuration combines several transmit and receive antennas in a smooth mast, which will reduce drag and snagging. Onboard engineering sensors will collect and store voltages, currents, pitch, roll, temperature, and other buoy performance data on a regular basis while the spar is submerged, and will send that information to the user when $R F$ communication is established. Safety features include backup
acoustic commands to the buoy and a GPS

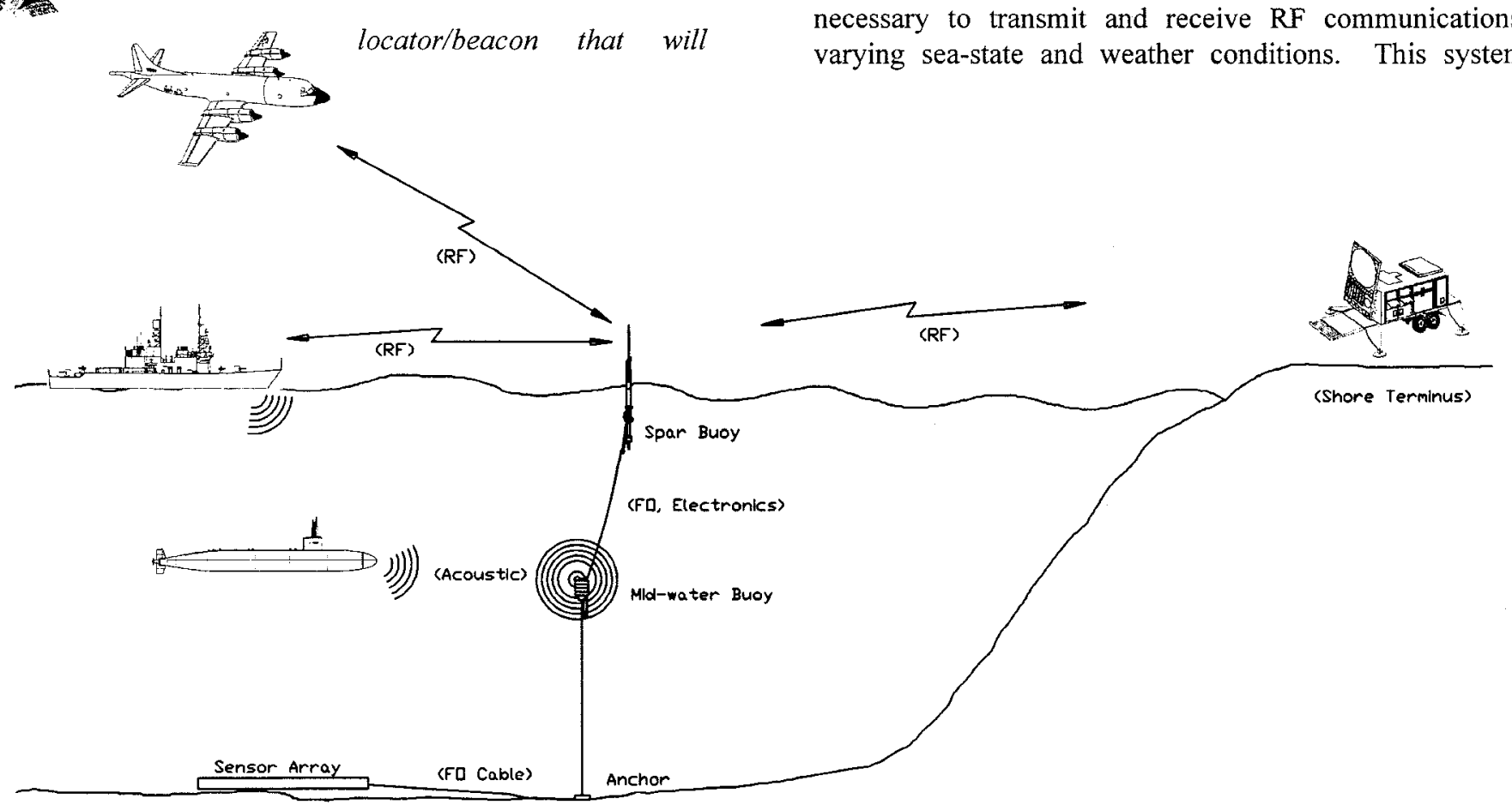

detect and report the spar's position should it break away from its mooring.

\section{Introduction}

Most long-term ocean-bottom sensor arrays requi : at a cable of some kind be laid across the ocean floor to carry data to the end user. This trunk cable is often the major factor that determines the cost, complexity, time, and in some cases the type of deployment necessary to completely install an operational system. Moreover, trunk cables are seldom buried, making them vulnerable to trawling rigs and anchors all along their length. Landing cables across a shoreline takes a great deal of additional hardware, planning, and execution. The Deployable Surveillance Technology Project sponsored by the Office of Naval Research (ONR), is developing buoy technology for sending data extracted from remotely deployed underwater sensor arrays to an end user via a reliable, secure radio link.

The Naval Command, Control and Ocean Surveillance Center Research Development Test and Evaluation Division (NRaD) has developed a single-point- moored submersible pop-up spar buoy system to provide a stable platform necessary to transmit and receive RF communications in varying sea-state and weather conditions. This system is 
designed to support a variety of high- and low-data-rate twoway radios for direct line-of-sight, over-the-horizon, and relayed RF communication (see figure 1). The submersible buoy will be able to avoid many of the environmental and man-made threats and hazards that plague typical cabled systems and full-time surface buoys.

The buoy is designed to connect to sensors on the sea floor via either acoustic transceiver or fiber optic cable. It accepts commands from the control terminus, relays commands to the sensors, and passes data from the sensors to the terminus. It is designed to spend most of it operational life submerged, away from the weather, surface effects, and visual identification. The spar section surfaces only when commurication is required and when conditions allow for a safe excursion to the surface. While on the surface, the only part of the buoy exposed to the atmosphere is a low profile antenna mast. Initial RF communication architecture was configured to be compatible with the Shallow Water Sensor String (SWSS) output of 2.5 megabits per second per channel.

\section{Design Considerations}

The buoy system is comprised of three major sections: the spar buoy, the mid-water buoy, and the anchor section. These are connected by two cable assemblies (see figure 2). The cables each contain three optical fibers and three shielded twisted electrical pairs. The electrical conductors convey power from the anchor to the buoys and control signals from the spar buoy to the mid-water buoy and the anchor. The optical fibers carry data from the sensors to the spar buoy for relay via $R F$ to the terminus, and commands from the terminus to the sensors. A bi-directional acoustic link replaces the optical fibers when the sensors are not connected by cable, and when the data rate is low. The acoustic link can also replace the RF command link for emergency buoy operation.

The RF link that was implemented for the initial buoy tests consists of a $9600 \mathrm{~b} / \mathrm{s}$ command channel from the terminus to the spar buoy, a $9600 \mathrm{~b} / \mathrm{s}$ buoy status channel, and a $2.5 \mathrm{Mb} / \mathrm{s}$ data channel from the spar buoy to the terminus. The command channel operates at $399.5 \mathrm{MHz}$ and the status and data channel operates at $1.77 \mathrm{GHz}$. All modulation is FSK. An additional VHF radio transceiver provides backup command capability and positioning information from the onboard GPS receiver in case of spar buoy breakaway.

The system primary power battery, an acoustic release, and the bottom clump anchor comprise the anchor section. In an operational configuration, these three components would be built into one housing; however, for ease in handling of the prototype, these components were distributed along the cable string. Eight 6-volt alkaline batteries were arranged in a series-parallel arrangement, providing a nominal 80 -amperehour, 24-volt supply to constantly recharge the spar buoy's battery system. This particular arrangement of batteries will support a thirty-day mission that includes 10 surface/dive cycles with 5 hours of full power RF transmission at each surface interval, plus the data logging and hotel load during the period when the spar is submerged.

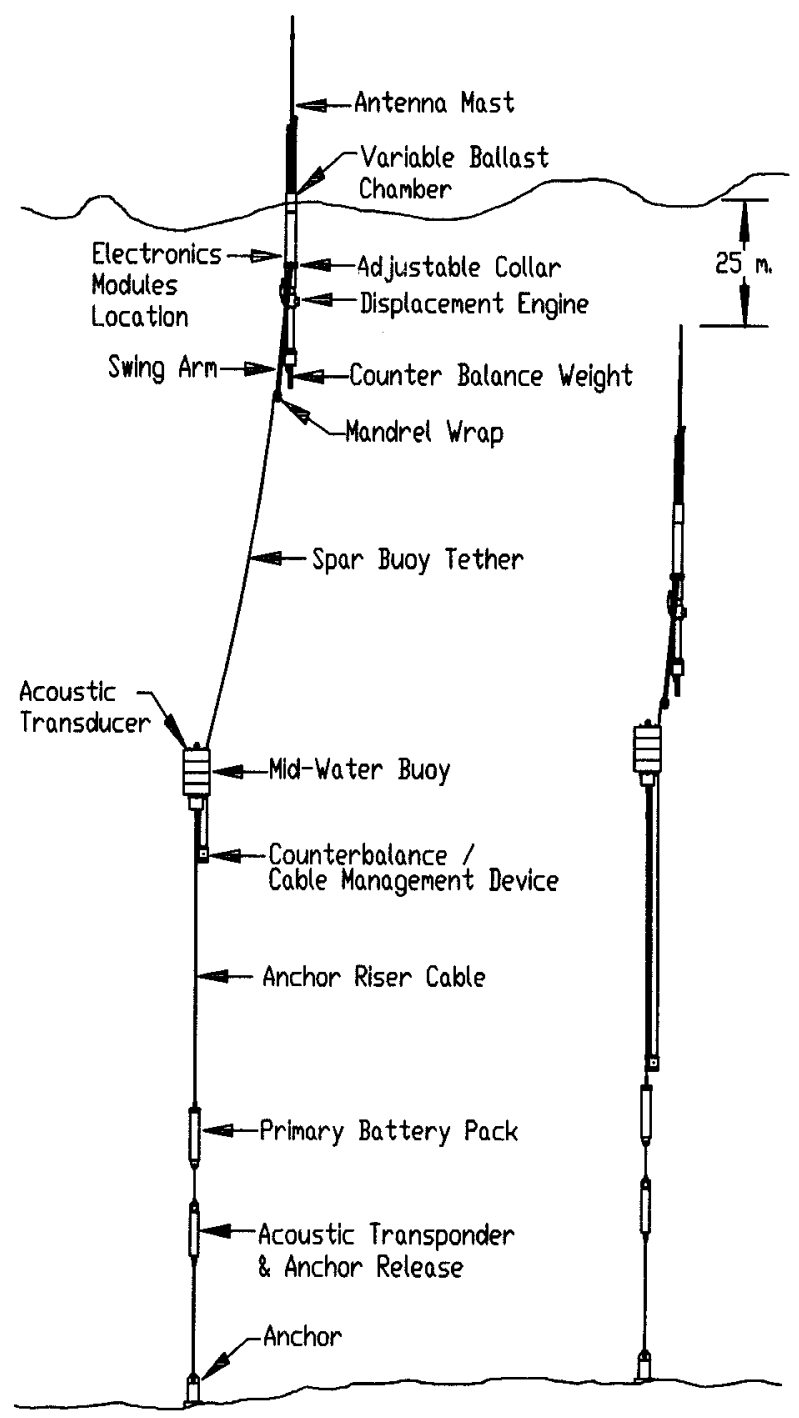

Fig. 2: Buoy System Configuration

A critical requirement of the buoy system is to provide a stable platform from which to transmit and receive RF signals. A spar configuration was selected due to its inherent nature to suppress motion due to wave action. It measures 6.52 meters from the top of the antenna mast to the bottom of the counterbalance weight: $3.73 \mathrm{~m}$. for the main body and $2.79 \mathrm{~m}$. for the antenna mast (see figure 3 ). The spar buoy is inherently positively buoyant at all times so that it will rise to the surface if it breaks free of its mooring. Even if the displacement piston is in its fully retracted position with the motor housing flooded, the spar has enough buoyancy to float to the surface. It is the combination of the spar, spar cable, counterbalance weight, and tether management system that establishes the near-neutral buoyancy and allows the pop-up mechanism to function properly. 


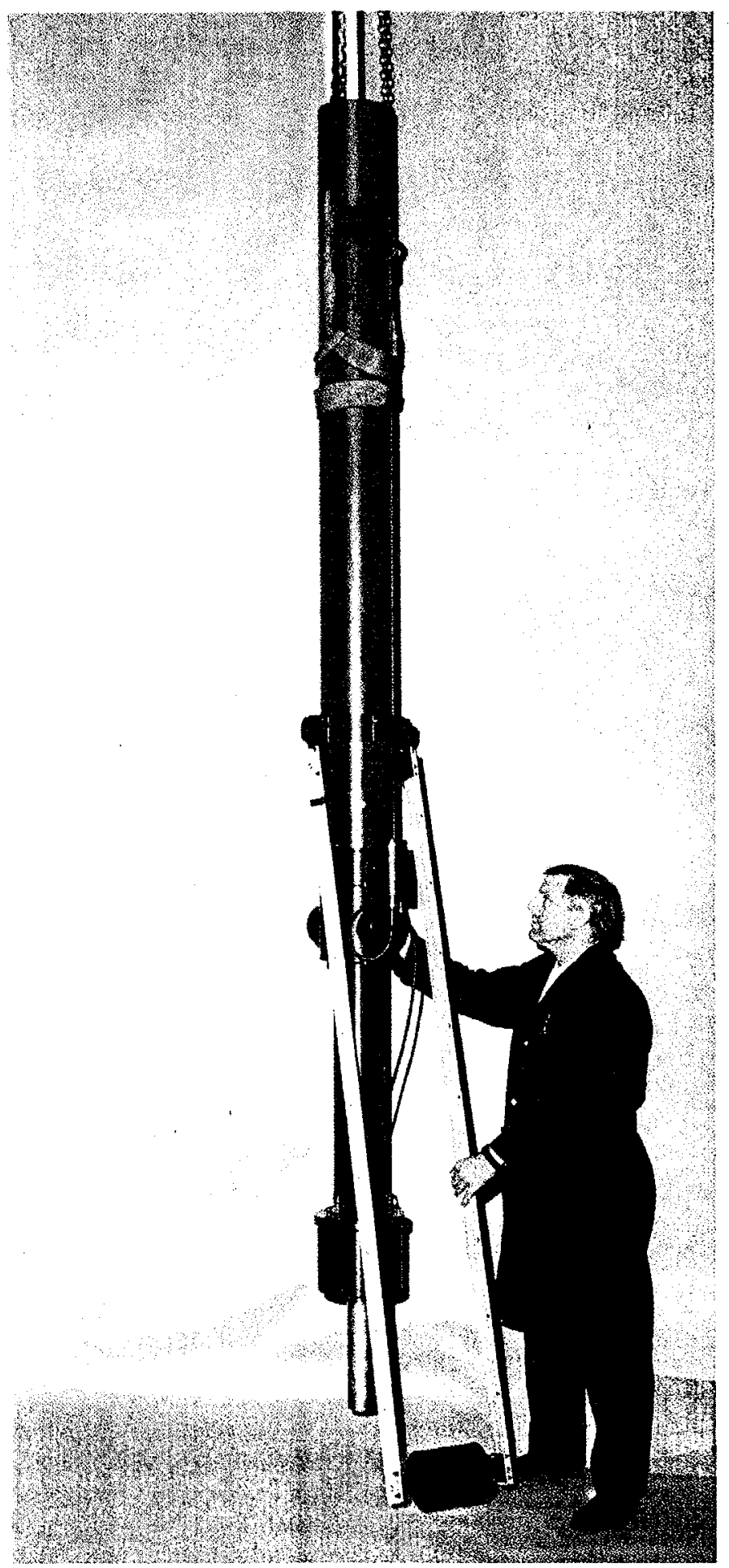

Fig. 3: Main Body of Spar Buoy

Because the spar is connected to the sensor array via an electro-opto-mechanical cable system, some method of cable management is necessary to allow full travel of the spar from depth to the surface. Tethering the spar buoy to the midwater buoy, while still providing a pop-up capability, involves the use of a special weighted pulley located beneath the midwater buoy. This tether management pulley rides along the anchor riser cable, tending the spar cable next to the anchor riser cable and eliminating the need for underwater electrical and optical slip rings (see figure 4). It is correctly weighted to maintain tension on the spar cable at all times and to allow the spar to move freely in the water column. An added feature of this device is to provide a constant forcing function to draw the spar next to the mid-water buoy (when submerged) without the need to expend any electrical power. The combination of the weighted pulley, spar cable and the variable ballast spar buoy allows the buoy system to change from $2.5-\mathrm{kg}$ negative displacement to $6.8 \mathrm{-kg}$ positive displacement when in the "surface" state.. The spar itself is free floating, and is allowed to "hover" around the mid-water buoy while it is submerged.

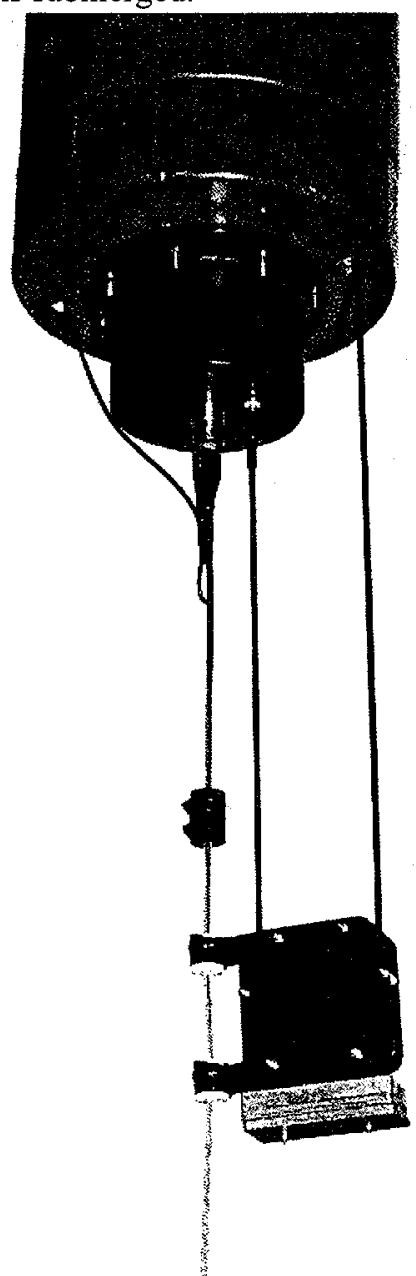

Fig. 4: Counterbalance Weight/ Cable Management Subsystem

\section{Mechanical Description of the Spar:}

The counter-balance weight at the bottom of the spar is designed to stabilize the spar section by providing separation between the center-of-buoyancy and the center-of-weight. This cylindrical weight also provides protection for the displacement engine's lead screw cover.

Above the counterbalance weight is a pressure bottle that contains the buoy system's secondary power supply of 
rechargeable sealed lead gel-cell batteries. This power supply is constantly recharged from the primary battery supply located in the anchor assembly and provides power to the spar and mid-water buoy. It is a 24/12-volt supply that has the capacity to drive the buoyancy engine through two dive cycles, provide for 5 hours of RF communication at full power to the transmitter, and supply the hotel load of the engineering sensors and data loggers. Also installed in the pressure bottle is a backup 12-volt alkaline power supply for the emergency GPS receiver and VHF transceiver. This power supply has an operational life of 4 days, time enough to locate the spar section should it break away from its moor. An external temperature probe is also the mounted on the pressure bottle.

A change in buoyancy is achieved through a motordriven piston that provides a 9-kg total change in displacement. This type of displacement engine is well suited for this type of application. The spar buoy needs only two states for operation: submerged and surfaced. Under normal operations, the buoy system will change its displacement from negative to positive after the motor-driven piston is fully extended. For safety purposes a drive screw was selected which is freewheeling at the stroke ends. Limit switches are installed at each end of the stroke to minimize power consumption and to provide a logic reference to determine the state of the displacement piston.

The main electronics module, primary UHF radio, and GPS modem and radio are installed in the spar directly above the displacement engine and inside the fixed buoyancy compartment. Two of the buoy system's four microcontrollers are located in the main electronics module. They control the power to the RF receiver, buoyancy engine, spar buoy sensors, and the GPS radio. They also set RF attenuation levels, monitor the RF communication line for valid commands from the user and respond appropriately, and monitor the state of the buoy system and compare it to the expected state to determine if a fault condition has occurred.

A variable ballast chamber located at the top of the spar main body limits the amount of surface exposure the spar will receive. When the buoyancy engine in the spar is fully extended, the overall change in displacement will allow the spar to rise to the surface. This design philosophy is different from hauling the buoy up and down by a cable. If the spar has an excess of buoyancy (due to a calm day with minimal current drag on the spar's cable) it will have a tendency to rise out of the water farther than necessary. The variable ballast chamber will cause the spar to lift water that is trapped inside this "cup" out of the water, thereby "taking on ballast" and limiting the surface exposure. This in turn increases the stability of the antenna mast by keeping the buoyancy and weight moments separated as far as possible.

Stability of the spar is further enhanced by the addition of a swing arm assembly that is attached at the center of drag.
It provides the mechanical termination for the spar cable and allows the spar to move with minimum influence of the cable pull. Surface currents and waves have little influence to heel the spar to one side, as equal forces will be applied on both sides of the attachment point. Overall, the addition of the swing arm allows the spar to remain within $15^{\circ}$ of vertical in a sea state of 2 or less.

The antenna mast contains three separate antennas: a $1770 / 400 \mathrm{MHz}$ dual-band UHF antenna, an end-fed half-wave $140 \mathrm{MHz}$ VHF antenna, and a hockey-puck GPS receive antenna. For proper operation, the mast is designed to keep the primary antenna approximately $2.8 \mathrm{~m}$ off the surface of the still water level, a height that will allow most waves to pass through the mast structure without swamping the antenna.

\section{The Mid-Water Buoy}

Spar buoys characteristically have small buoyancy-todrag ratios and are ineffective in supporting long mooring lines. Adding a mid-water buoy of sufficient positive buoyancy eliminates unnecessary loading on the spar and provides correct tensioning on the riser cable to allow the counterbalance weight and tether management components to operate properly. It is composed mostly of lightweight syntactic foam. This subsurface buoy also acts as a docking station for the submerged spar buoy (see figure 4). For optimum performance of the buoy system the mid-water buoy is positioned 30 meters below the surface A pressure sensor monitors the depth of the buoy. At this depth, the influence of surface waves is minimized, providing a relatively calm environment for the spar. It is also shallow enough to allow divers to visit the buoy if necessary.

A pressure bottle located at the bottom of the syntactic foam body contains the acoustic transceiver, control electronics, a separate battery supply and a pressure gauge. The third of the four micro-controllers controlling the buoy system is contained in this electronics package. Its purpose is to alert the master controller upon receiving acoustic commands from the surface and to forward responses from the master controller back to the acoustic unit for relay to the sender.

\section{Anchor Section}

As mentioned previously, the anchor section in the initial configuration was distributed along the buoy string for ease incorporating the release capabilities with the primary batteries. However in an operational configuration, the primary batteries and acoustic release would be incorporated into the anchor. External connection ports would also be built into the anchor assembly so that sensor arrays could be attached to the buoy. These external ports can be configured for wet- or dry-mateable capabilities to suit the operational needs. 


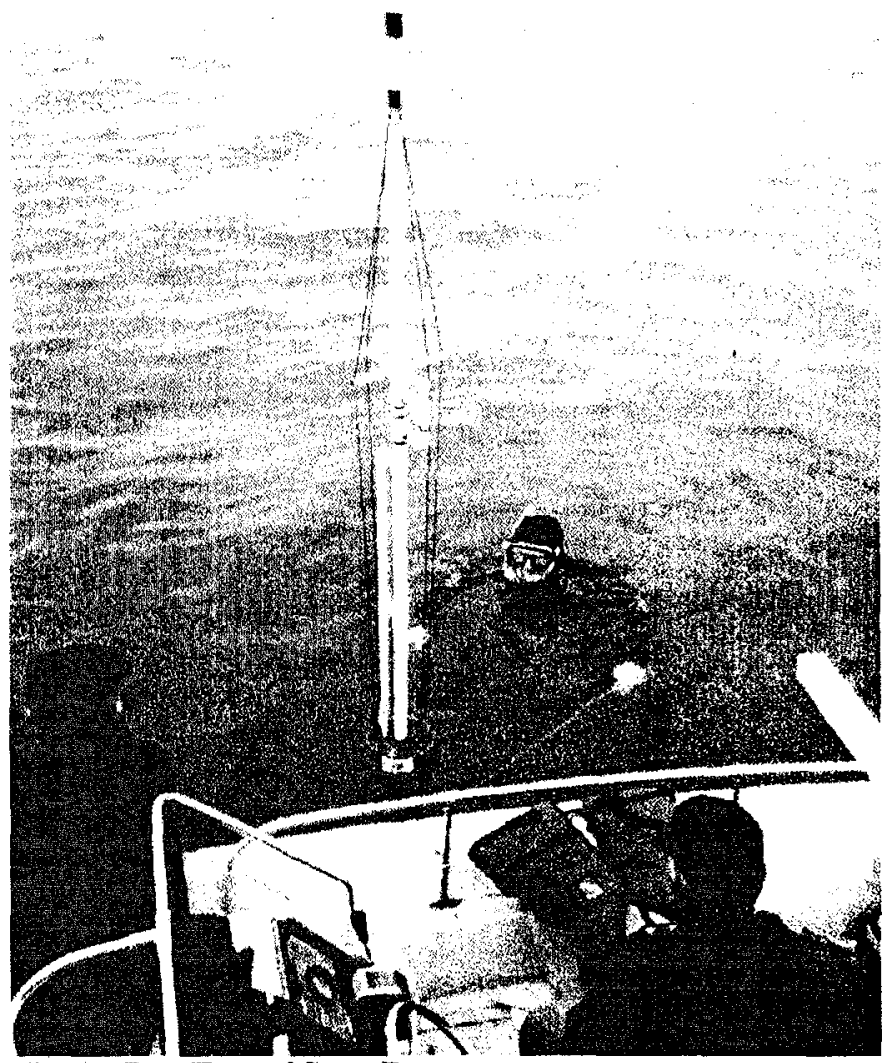

Fig. 5: Bay Test of Spar Buoy

\section{Safety Features:}

Many features were incorporated into the buoy system to give it the ability to remain on station and operational even under a degraded state. Sensors on the spar can detect a high sea state condition, causing it to submerge automatically. This removes the spar from high mechanical and snap loading conditions thereby allowing it to remain on station through most all sea-state conditions. A back-up acoustic command link built into the mid-water buoy provides communication to the spar while it is submerged. This acoustic link is presently limited to two basic commands: Stay Down until called, and Surface Now. Power is distributed throughout the system so that a failure at one point in the system will not simultaneously bring down all of the systems at once. A GPS finder subsystem provides a means of locating the spar in the event it breaks away from its moor. In an emergency, the GPS finder circuits activate and draw power from a separate and isolated battery supply. Overall this system can adjust itself to accommodate a variety of sea-states and allow a graceful degradation throughout its operational life.

\section{Results of Bay Tests:}

For the initial tests, the spar buoy system was not connected to a sensor array, and the optical fiber link from the spar was left unterminated at the anchor battery bottle. On Feb 26, 1997 the spar buoy was deployed in the San Diego Bay to exercise the various system parameters, verify the radio performance, and test the safety features built into the buoy (see figure 5). The shore station was positioned approximately $1.6 \mathrm{~km}$ distance from the spar's deployment site (see figure 6). After initial weight and balance adjustments, the spar was towed to a location (approximately $90 \mathrm{~m}$ from the $\mathrm{NRaD}$ piers) that provided $21 \mathrm{~m}$ of water depth. Initial radio tests indicated good communication to and from the spar. Commands were received and executed by the

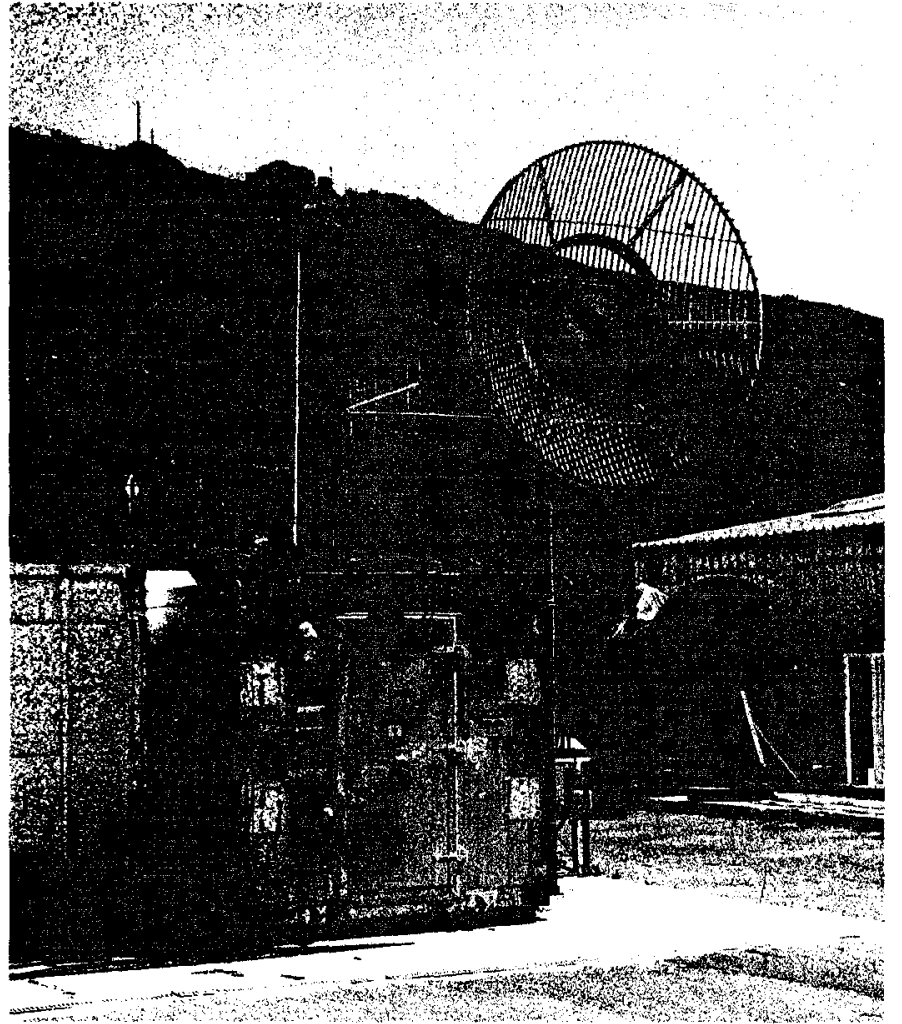

Fig. 6: Shore Station Van

spar as expected, and data was sent back to the shore station with expected bit errors. A dive command was then sent over the RF link and the buoy correctly commanded the buoyancy engine to pull in the piston and submerge the buoy. Unfortunately an incorrect return-to-surface command was entered into the spar's command database. Since the buoyancy engine was in the fully submerged state, the only means available for commanding the buoyancy engine to "surface" the spar was through the acoustic link. However, a failure in the surface deck unit of the acoustic transponder prevented contacting the spar and commanding the buoyancy engine to push the piston out to the full surface condition. Without any immediate means of resetting the spar's buoyancy engine, the bay test was halted and the hardware was recovered. 


\section{Future Plans}

The buoy system suffered casualties in earlier deep-sea tests due to manufacturing defects in several critical mechanical components. These were corrected before the February 1997 tests in San Diego Bay. Additional enhancements to the system are planned prior to re-instituting tests at sea. These include changes in the radios, software, and control electronics. An alternate antenna structure will be tested, which consists of a single lightweight vertical whip and a GPS receive antenna. The whip will service all the command, control, status, data, and GPS finder functions. There are no plans to alter the mechanical system, other than to incorporate hybrid fiber-optic/electrical connectors in the riser and tether cables.

\section{Acknowledgements}

This work was sponsored by the ONR Sensors, Sources, and Arrays Program (321SS). The authors thank Mr. Ken Dial and Dr. Don Davison for their support. 